\title{
Traumatic macular holes: to operate, or not to operate, that is the question
}

\author{
Aristomenis Thanos ${ }^{1}$, Bozho Todorich ${ }^{2}$ \\ ${ }^{1}$ Legacy Devers Eye Institute, Portland, OR, USA; ${ }^{2}$ Pennsylvania Retina Specialists, PC, Camp Hill, PA, USA \\ Correspondence to: Aristomenis Thanos, MD. Legacy Devers Eye Institute, Portland, OR 97210, USA. Email: athanos@lhs.org. \\ Provenance and Peer Review: This article was commissioned by the editorial office, Annals of Translational Medicine. The article did not undergo \\ external peer review. \\ Comment on: Chen HJ, Jin Y, Shen LJ, et al. Traumatic macular hole study: a multicenter comparative study between immediate vitrectomy and six- \\ month observation for spontaneous closure. Ann Transl Med 2019;7:726.
}

Submitted Apr 01, 2020. Accepted for publication Apr 30, 2020.

doi: $10.21037 / \mathrm{atm} .2020 .04 .50$

View this article at: http://dx.doi.org/10.21037/atm.2020.04.50

Ever since the observation that idiopathic macular holes (IMH) can be successfully managed by means of pars plana vitrectomy, a once inoperable condition became one of the surgeries with the highest success rate in vitreoretinal surgery (1). Indeed, advances in surgical techniques and instrumentation have led to a primary anatomic success rate of more than $95 \%$ for uncomplicated IMHs (2). On the other hand, significant challenges to vitreoretinal surgeons pose unique clinical scenarios with chronic and/ or large macular holes, as well as macular holes associated with trauma, where success rates for hole closure and visual improvement decrease considerably.

In contrast to the IMHs, traumatic macular holes (TMHs) have a high rate of spontaneous closure. Reported rates of spontaneous closure of TMHs of $37-44 \%$ occur within the first two months after the injury (3). Comparatively, rate of spontaneous closure of IMHs is in the $2.7-6.2 \%$ range $(4,5)$. Various factors have been postulated to play a role in this observed difference, including the relatively younger age of patients with TMHs and the intact posterior hyaloid, which may act as a scaffold for the re-approximation of the retinal edges. Furthermore, hole size and spectral domain optical coherence tomography (SD-OCT) features appear to have a prognostic value as well, since smaller hole size $(<250 \mu \mathrm{m})$ and absence of any intraretinal edema are favorable imaging criteria for spontaneous hole closure (6). Guided by these imaging biomarkers and known natural history of TMHs, clinicians have traditionally resorted to observation as the initial management of TMHs, followed by vitrectomy if the TMH fails to close with observation alone. Yet, there may be cases where early surgical intervention is warranted, but evidence to guide our approach on this is lacking.

The study by Chen et al. was the first multicenter, prospective, comparative case study that attempted to address the outcomes of patients with TMHs comparing observation to early vitrectomy (7). Authors reported that early vitrectomy resulted in significantly higher rate of TMH closure compared to initial observation $(100 \%$ vs. $66.7 \%$, respectively). Yet, despite the superior anatomic effects of vitrectomy surgery, there was no difference in final visual acuity between surgically closed or spontaneously closed macular holes. In the observation group, $80 \%$ of spontaneously closed TMHs did so within the first 3 months. Presence of cystoid macular changes on SDOCT imaging was identified as an adverse factor in facilitating spontaneous closure. Taken together, the authors reported a high rate of spontaneous closure but even higher with early surgical intervention. They concede, however, that a 3-month observation period after injury may be an acceptable initial first step in patient management.

These are important findings as clinicians often struggle to identify the ideal timepoint of when to offer surgical intervention to TMH patients. Considering that TMHs are often observed in younger patients and children with formed vitreous, observation aimed at spontaneous closure that would preclude surgical manipulation of the vitreous may be optimal, especially in centers that do not routinely 
perform pediatric vitrectomies. The length of observation must be balanced by the risk of permanent outer retinal and retinal pigment epithelium (RPE) changes that could be prevented, at least in part by the immediate surgical closure of TMHs. Although the study design by Chen et al. did not allow physicians to guide their patients and provide any recommendation, it is the rest of retina community that can benefit from this study extrapolating useful conclusions, formulate treatment plans based on scientific evidence and sound clinical research about this potentially vision threatening condition.

\section{Acknowledgments}

Funding: None.

\section{Footnote}

Conflicts of Interest: Both authors have completed the ICMJE uniform disclosure form (available at http://dx.doi. org/10.21037/atm.2020.04.50). The authors have no conflicts of interest to declare.

Ethical Statement: The authors are accountable for all aspects of the work in ensuring that questions related to the accuracy or integrity of any part of the work are appropriately investigated and resolved.

Open Access Statement: This is an Open Access article distributed in accordance with the Creative Commons Attribution-NonCommercial-NoDerivs 4.0 International License (CC BY-NC-ND 4.0), which permits the non- commercial replication and distribution of the article with the strict proviso that no changes or edits are made and the original work is properly cited (including links to both the formal publication through the relevant DOI and the license). See: https://creativecommons.org/licenses/by-nc-nd/4.0/.

\section{References}

1. Kelly NE, Wendel RT. Vitreous surgery for idiopathic macular holes. Results of a pilot study. Arch Ophthalmol 1991;109:654-9.

2. Zhao PP, Wang S, Liu N, et al. A Review of Surgical Outcomes and Advances for Macular Holes. J Ophthalmol 2018;2018:7389412.

3. Budoff G, Bhagat N, Zarbin MA. Traumatic Macular Hole: Diagnosis, Natural History, and Management. J Ophthalmol 2019;2019:5837832.

4. Sugiyama A, Imasawa M, Chiba T, et al. Reappraisal of spontaneous closure rate of idiopathic full-thickness macular holes. Open Ophthalmol J 2012;6:73-4.

5. Yuzawa $M$, Watanabe A, Takahashi $Y$, et al. Observation of idiopathic full-thickness macular holes. Follow-up observation. Arch Ophthalmol 1994;112:1051-6.

6. Chen H, Chen W, Zheng K, et al. Prediction of spontaneous closure of traumatic macular hole with spectral domain optical coherence tomography. Sci Rep 2015;5:12343.

7. Chen HJ, Jin Y, Shen LJ, et al. Traumatic macular hole study: a multicenter comparative study between immediate vitrectomy and six-month observation for spontaneous closure. Ann Transl Med 2019;7:726.
Cite this article as: Thanos A, Todorich B. Traumatic macular holes: to operate, or not to operate, that is the question. Ann Transl Med 2020;8(15):916. doi: 10.21037/atm.2020.04.50 